\title{
Contraceptive prevalence and factors influencing utilization among women in Pakistan: a focus on gender-based violence
}

\author{
Thao Thi Nguyen and Sarah Neal
}

Social Statistics and Demography, University of Southampton, Southampton, UK

\begin{abstract}
Purpose - In this study, the authors determined the prevalence of contraceptive use among Pakistani women and assessed factors influencing the utilization of contraception with a particular focus on the experience of gender-based violence.

Design/methodology/approach - The dataset used in this study was the Pakistan Demographic Health Survey 2018, which includes married women only. Bivariate analysis and multivariate logistic regression were used to investigate the association between contraceptive use and a number of explanatory variables including experience of gender-based violence.

Findings - From 2006 to 2018, the contraceptive prevalence rate (CPR) and the use of modern contraceptive methods increased slowly. The findings of this study demonstrated that higher educational level and wealth index increased the likelihood of contraceptive uptake and the use of modern contraception. Media exposure to family planning and spousal communication were protective factors that encouraged women to use contraception, including modern contraception, to avoid unwanted pregnancy. Women who experienced gender-based violence (GBV) were more likely to use contraception than women who did not experience GBV. Research limitations/implications - The use of secondary data limited the variety of important variable that should be investigated including knowledge of women on SRH, the attitude of women toward SRH and family planning, the skills of a healthcare provider on counseling family planning, and other barrier variables such as transportation and willingness to pay for contraceptive methods. 10; The sensitivity of the topic is considered as another challenge when collecting data. Women might be hesitant to share about their GBV experience. The experience to GBV is also hard to define and depends on the feeling of each person, especially emotional violence.

Originality/value - This paper is one of the very few studies to examine the association between GBV and contraceptive use, and thus is valuable in opening up debate about the links between these two factors.
\end{abstract}

Keywords Contraceptive, Gender-based violence, Pakistan

Paper type Research paper

\section{Introduction}

Sexual and reproductive health (SRH) is one of the major global health challenges in many countries in the world, especially for women. In the United Nations' Sustainable Development Goals (SDGs), SRH care is mentioned in Goal 3 which seeks to ensure that there is universal

(c) Thao Thi Nguyen and Sarah Neal. Published in Fulbright Review of Economics and Policy. Published by Emerald Publishing Limited. This article is published under the Creative Commons Attribution (CC BY 4.0) license. Anyone may reproduce, distribute, translate and create derivative works of this article (for both commercial and non-commercial purposes), subject to full attribution to the original publication and authors. The full terms of this license may be seen at http://creativecommons.org/licences/by/4.0/ legalcode

This paper was based on Nguyen Thi Thao's master's dissertation at Southampton University in the United Kingdom. The dataset for this study came from the 2018 Pakistan Demographic Health Survey. Permission to use the data set was given on 6 May 2020, and it was downloaded from the PDHS program website (www.PDHSprogram.com) on 22 June 2020.

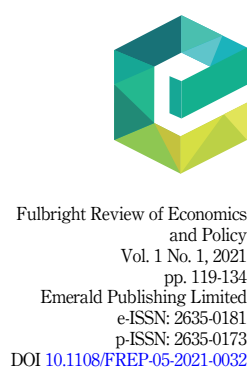


FREP

1,1 access to sexual and reproductive healthcare services, including family planning, information and education.

Violence against women, also known as gender-based violence (GBV), is "now widely recognized as a serious human rights abuse" as well as "an important public health problem that concerns all sectors of society" (World Health Organization [WHO], 2005; Hong Nguyen et al., 2012). The adverse health consequences of GBV for women's health are not limited to physical and mental well-being but also encompass their reproductive health (WHO, 2005; Sarkar, 2008; Hong Nguyen et al., 2012;). In addition, considerable research has been conducted which revealed negative effects of GBV on sexual autonomy, unwanted pregnancy and induced abortion (Emenike, Lawoko, \& Dalal, 2008; Silverman, Gupta, Decker, Kapur, \& Raj, 2007).

Pakistan is one of the countries with the highest imbalance of gendered power that favors men because of the patriarchal system (Hadi, 2017). Under the prevailing social norms, women are considered men's dependents (Mumtaz, Salway, Shanner, Bhatti, \& Laing, 2011). Women's decision-making is limited, and they have little independence in determining their economic and social identity (Mumtaz et al., 2011). All these limitations make women more vulnerable to violence. They suffer from many abnormal, harmful or abusive practices, such as rape, sexual assault, forced marriage and domestic violence (Hadi, 2017). Education for girls and women is also inadequate, with evidence of low levels of literacy among women (45\%) compared to men $(69 \%$; Saqib \& Ahmad, 2014).

In Pakistan, gender disparity is evident in the country's ranking of 141 out of 142 countries with respect to economic opportunities for and political participation of women (Hadi, 2017). According to the United Nations Development Programme's (UNDP) 2014 gender inequality index, Pakistan ranks 120 out of 150 countries. Gender disparity weakens women's position in society and family, making them more vulnerable to violence (Hadi, 2017). GBV may limit women's control over their fertility, thus reducing contraception use or interrupting the effective use of contraceptive methods (Hindin, Kishor, \& Ansara, 2008; Miller, Jordan, Levenson, \& Silverman, 2010; Pallitto, Campbell, \& O'Campo, 2005). Eliminating all forms of violence against all women and girls in the public and private spheres is the main objective of the SDGs under Goal 5: Gender Equality, and specific in target 5.2: Eliminate all forms of violence against all women and girls in the public and private spheres, including trafficking and sexual and other types of exploitation.

SRH care for women in Pakistan is still a significant issue that needs more involvement by the government, civil society organizations (CSOs) and other stakeholders for improvement. The percentage of women accessing family planning is still low, particularly modern methods. According to the Pakistani Demographic and Health Survey (PDHS) program report, in 2013, only 35\% of married women of reproductive age used some form of contraception, and only $26 \%$ of them used a modern method (PDHS, 2013). Compared to other countries in the region, Pakistan has a lower utilization rate of modern methods; for example, the rate is $43 \%$ in Nepal and $52 \%$ in Bangladesh (Howse \& Nanitashvili, 2014). This might account for Pakistan's high total fertility rate of 3.8 children per woman (PDHS, 2013).

According to the 2012-2013 PDHS, the prevalence of sexually active women who do not use contraception was $46 \%$, with about $37 \%$ of these women residing in urban areas and $53.2 \%$ in rural areas (Aslam, Zaheer, Qureshi, Aslam, \& Shafique, 2016). Among women living in urban areas, women who had higher education were more likely to use contraceptive methods. Approximately $55 \%$ of women with no education used contraception, while more than $70 \%$ of women with higher education used family planning and around $67 \%$ of women with secondary education used contraception (Aslam et al., 2016). This trend was similar to what was observed for women living in rural areas. Nearly $58 \%$ of women with higher 
education used family planning methods, while only more than $42 \%$ of women with no education used contraception (Aslam et al., 2016).

Three types of contraceptive methods are used in Pakistan: traditional, folkloric and modern methods. Modern methods include the pill, male condom, intrauterine device (IUD), injectable implant, emergency contraceptive, and female and male sterilization. Traditional methods are rhythm and withdrawal (PDHS, 2013). Folkloric contraceptive methods refer to local methods and spiritual methods of unproven effectiveness, for example, amulets, herbs and beads (Namasivayam, Lovell, Namutamba, \& Schluter, 2020). From 1990 to 2013, the percentage of women using traditional and folkloric methods was stable, less than $10 \%$. However, the percentage of women using modern methods increased significantly from approximately $20 \%$ to nearly 50\% (PDHS, 2013; Imran, Nasir, \& ZaidI, 2015).

To improve maternal health and increase contraception use among women in Pakistan, more research should be conducted to understand the factors that influence women's health as well as protect women from violence. Some studies in different contexts have been conducted to prove an association between violence against women and contraceptive utilization. Gomez (2011) found a negative association between intimate partner violence and current contraception use. Paul (2010) reported that Pakistani men who perpetrate domestic violence indicated that they use economic control as a tool for a sense of power and threatened the independence of their wives. This might be one of the barriers that limit women's access to contraception. However, in Bangladesh, the impact of GBV on contraception use was positive in Dalal et al.'s (2012) study. They found that women who experienced physical violence were 1.93 times more likely to use contraceptive methods (Dalal, Andrews, \& Dawad, 2012).

In this study, we determined the prevalence of contraception use among Pakistani women and with a focus on GBV and assessed the factors influencing contraception use. The following research questions guided the study: What is the prevalence of contraception use among women in Pakistan? What are the factors that influence contraception use among women in Pakistan? In particular, is experience of GBV associated either positively or negatively with contraception use?

\section{Methodology}

\subsection{Data source}

Data were extracted from the 2017-2018 PPDHS of married women, including information on women's background, reproduction, contraception, fertility preferences, husband's background and domestic violence. Data from 2,789 women who (1) completed the domestic violence module (2) were not pregnant at the time of the survey, and (3) their current marriage is their first marriage were used for analysis.

The 2017-18 PDHS followed a stratified two-stage sample design. The stratification was achieved by separating each of the eight regions into urban and rural areas. The 2017-18 PDHS included all ever-married women age 15-49. Those who were either permanent residents of the selected households or visitors who stayed in the households the night before the survey were eligible to be interviewed. In these households, one eligible woman in each household was randomly selected to be asked additional questions about domestic violence.

\subsection{Data analysis}

Descriptive analyses including frequencies, cross-tabulations and Pearson chi-square test were conducted to demonstrate a primary understanding of the data and to prepare for binary logistic regression. Multivariate binary logistic regression was used to identify the association between independent variables and dependent variables. The two main dependent variables in this study were Current contraception use and Type of 
FREP

1,1

122

contraceptive method. Current contraception use was defined as "Yes" and "No." Type of contraceptive method was categorized as "modern methods" and "traditional methods." Independent variables which had significant associations with dependent variables from the results of the Pearson chi-square test were included in the logistic regression models. The final model included Age groups, Region, Women's education level, Wealth index, Media exposure on family planning, Number of living sons, Number of living daughters and Experience of any type of $G B V$.

\section{Results}

\subsection{The prevalence of contraception use among Pakistani women}

After a decade (from 2006 to 2018), there was a slight increase from $29.6 \%$ to $35.7 \%$ in the prevalence of current contraception use among Pakistani women. From 2012 to 2018, the percentage of women using any contraception at the time of interviewing was stable around 35\% as shown in Figure 1 (PDHS, 2008, 2013, 2019).

There was an increase in use of traditional and modern methods from 2006 to 2018; however, the percentage of women who currently use modern contraception was stable at around 26\% from 2012 to 2018 (PDHS, 2008, 2013, 2019). The increase in use of modern methods was slow with only about $5 \%$ after 10 years as shown in Figure 1.

The prevalence of contraception use among different groups is shown in Table 1. In general, women aged 30-44 years had a higher tendency to use contraception than younger age groups $(36.7 \%$ vs $17.1 \%$, $p$-value $<0.001)$. Moreover, $14.4 \%$ of women aged $30-34$ years used traditional methods, but only $4.4 \%$ in the age $15-19$ years. These differences in contraception use and modern methods among age groups were statistically significant at $p$ value $<0.001$. A higher number of urban women used contraception than rural women, irrespective of whether the contraceptives used were modern $(32.2 \%$ vs $26.8 \%)$ or traditional methods $(14.9 \%$ vs $7.8 \%$, respectively). There was a statistically significant difference in contraception use among regions in Pakistan ( $p$-value $<0.001)$. Islamabad Capital Territory (ICT) and Punjab had higher percentage of women using contraception than Sindh, Khyber Pakhtunkhwa (KPK), Balochistan and Federally Administered Tribal Areas (FATA).

In terms of the wealth index variable, wealthier women had a higher tendency to use contraception and modern contraceptive methods than poorer women $(\phi$-value $<0.001)$. About $53 \%$ of the richest women used contraception compared to only $24.3 \%$ of the poorest women. More than $35 \%$ of the richest women used modern contraceptive methods, compared to only about $20 \%$ of the poorest women.

Figure 1.

The prevalence of contraceptive utilization among Pakistani women from 2006-2007 to 2017-2018

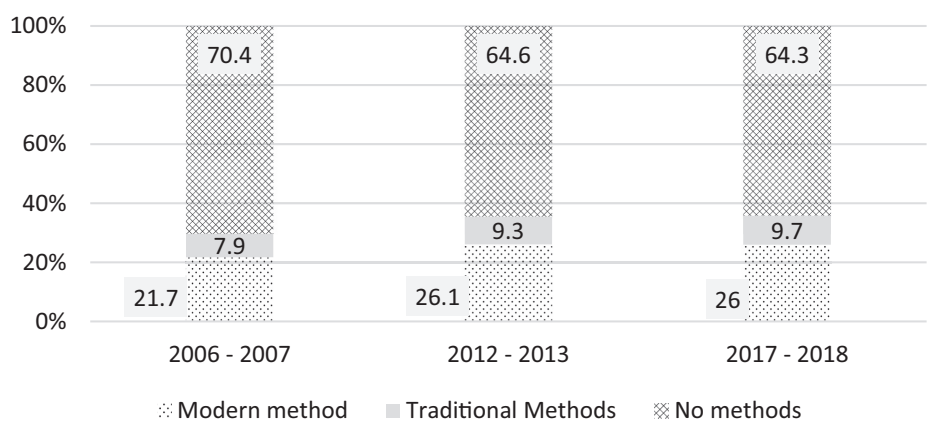

Source(s): Author's work, PDHS, 2018 


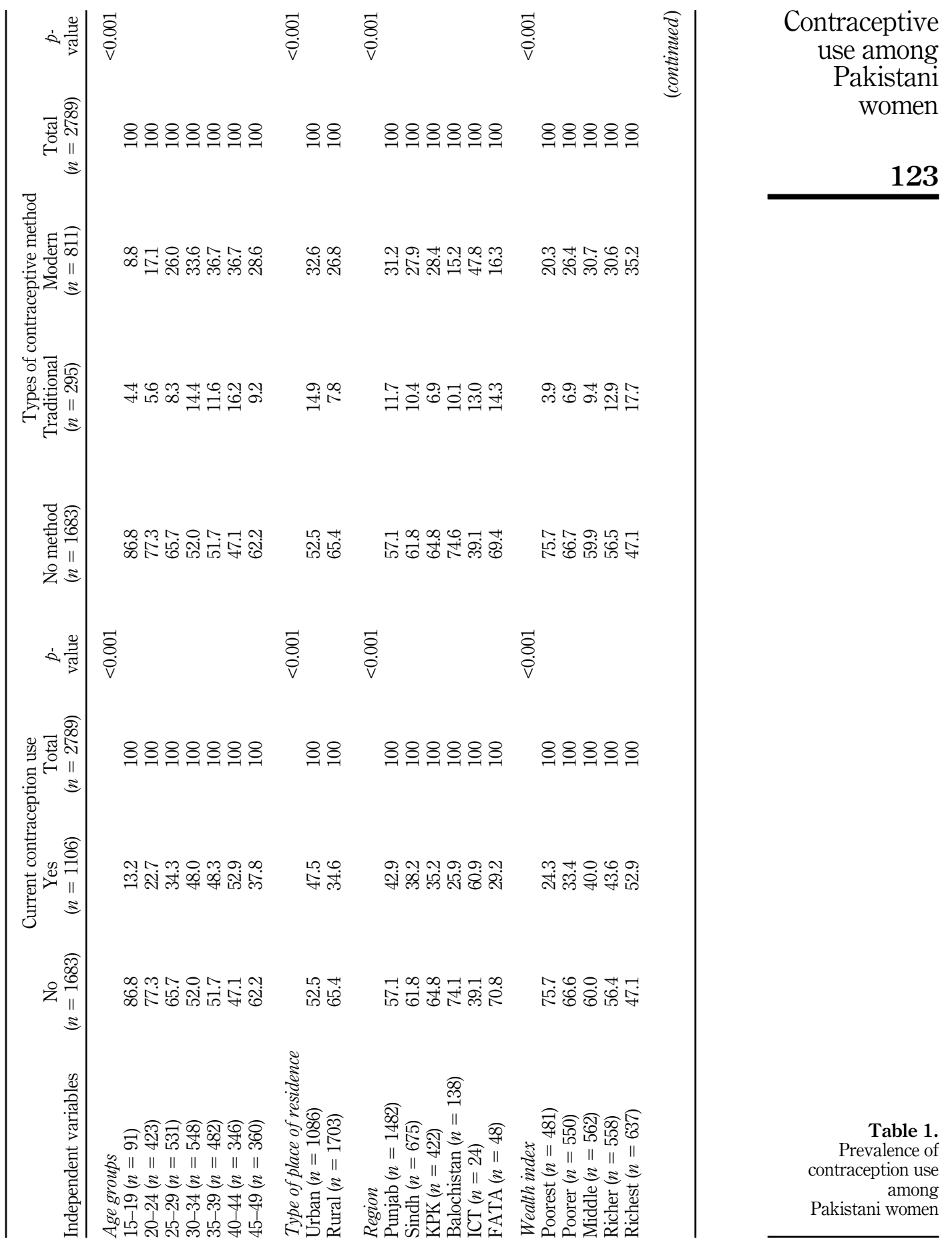


FREP
1,1

124

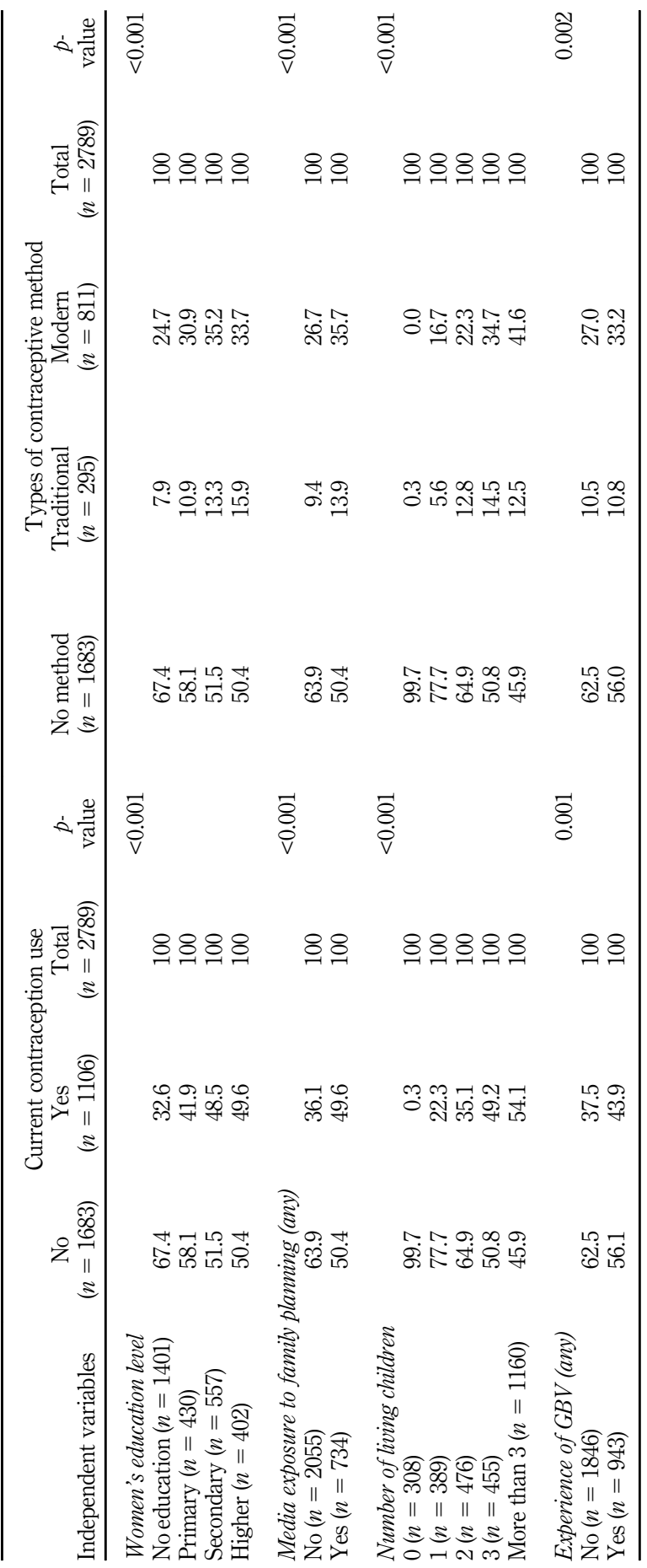

Table 1. 
Additionally, as for education level, women with higher education used contraception in general and modern contraceptive methods more than women with lower education ( $p$-value $<0.001$ ). A higher proportion of women who had heard about family planning in media channels used contraception $(49.6 \%)$ and modern methods $(35.7 \%$; $p$-value $<0.001)$. Also, women who had a higher number of living children used contraception and modern methods more than women who had a smaller number of living children $(p$-value $<0.001)$. Women who had a higher number of living sons had a higher tendency to use contraception than women with a lower number of living sons.

As for the GBV experience variable, about $44 \%$ of women who experienced at least one type of GBV used contraception in general, and $33.2 \%$ of women who experienced GBV used modern methods compared to $38 \%$ and $27 \%$, respectively, for those who had not experienced GBV. The proportion of women who used traditional methods was similar in two groups of women with around $10.5 \%$. The difference in contraception use among different groups of women who experienced at least one type of GBV was statistically significant ( $p$-value $<0.01$ ).

\subsection{Factors associated with contraception use using binary logistic regression}

The factors associated with contraception use are shown in Table 2. Results from multivariate logistic regression showed positive association between age groups, educational level, wealth index, exposure to family planning information in the media, number of living children and experience of GBV with contraception use.

In general, compared to women age 15-19 years, those aged 45-49 were less likely to use contraception in general (Odd ratio-OR: 0.241, $p$-value $<0.010$ ) and modern contraceptive methods (OR: $0.387, p$-value $<0.050$ ). Additionally, there was a positive association between women's education level and their use of contraception. Women who had more education were more likely to use contraception than women who had no education (OR: $2.202, p$ value $<0.010$ ). Women with higher education were also more likely to use modern methods than the reference group, women who had no education (OR: 2.074, $p$-value $<0.010)$.

Furthermore, family planning communication appears to be a factor that encouraged women to use contraception. Pakistani women who were exposed to family planning information in media channels were more likely to use contraception in general (OR: $1.265, p$ value $<0.050)$ and modern methods (OR: 1.244 , $p$-value $<0.050)$ than women who were not exposed to family planning information in media channels. Besides, in comparison to the reference group (women in the lowest household income group), a higher wealth index increased the likelihood of contraception use and modern methods. Women in the highest household income group were more likely to use contraception in general (OR: 4.352, $p$ value $<0.010)$ and modern methods (OR: 2.034, $p$-value $<0.010)$ than the reference group.

The number of living children including sons and daughters had a positive association with contraception use in general and modern methods. Women who had more than one living son were more likely to use contraception (OR: 4.677, $p$-value $<0.010)$ and modern methods (OR: $3.688, p$-value $<0.010$ ) than the reference group (women who did not have sons). Women who had one daughter were also more likely to use contraception (OR: 2.822, $p$ value $<0.010)$ and modern methods $(\mathrm{OR}: 1.884$, $p$-value $<0.010)$ than the reference group (women who did not have daughters). Interestingly, the strength of the coefficient was higher for living sons than for living daughters. This result means that having a certain number of living sons increases the likelihood of using contraception when compared with a certain number of living daughters.

Experience of GBV was also a predictor that explains contraception use. Women who had experienced violence were more likely to use contraception than women who had not experienced violence $(\mathrm{OR}: 1.223, p$-value $=0.040)$. The results also showed that among women who experienced violence, education level and wealth index had a positive association
Contraceptive use among Pakistani women 


\section{FREP}

1,1

Variable

Current contraception use

Use modern contraceptive

Region

OR

95\% CI for OR method

Punjab $(n=1482)$

126

Sindh $(n=675)$

KPK $(n=422)$

Balochistan $(n=138)$

ICT $(n=24)$

FATA $(n=48)$

\begin{tabular}{lr}
\multicolumn{2}{c}{ Reference category } \\
0.986 & $(0.791-1.230)$ \\
$0.717 *$ & $(0.549-0.937)$ \\
$0.417 * *$ & $(0.263-0.662)$ \\
1.639 & $(0.640-4.195)$ \\
0.622 & $(0.308-1.255)$
\end{tabular}

Age group

15-19 $(n=91)$

20-24 $(n=423)$

$25-29(n=531)$

$30-34(n=548)$

35-39 $(n=482)$

40-44 $(n=346)$

45-49 $(n=360)$

Women's education level

No education $(n=1401)$

Primary $(n=430)$

Secondary $(n=557)$

Higher $(n=402)$

Exposure to media

No $(n=2055)$

Yes $(n=734)$

\begin{tabular}{lr}
\multicolumn{2}{c}{ Reference category } \\
0.870 & $(0.426-1.778)$ \\
0.684 & $(0.335-1.394)$ \\
0.731 & $(0.355-1.504)$ \\
0.549 & $(0.263-1.146)$ \\
0.516 & $(0.242-1.100)$ \\
$0.241 * *$ & $(0.112-0.520)$
\end{tabular}

\begin{tabular}{ll}
\multicolumn{2}{c}{ Reference category } \\
$1.365^{*}$ & $(1.034-1.802)$ \\
$1.609^{* *}$ & $(1.215-2.131)$ \\
$2.202^{* *}$ & $(1.578-3.073)$
\end{tabular}

Wealth index

Poorest $(n=481)$

Poorer $(n=550)$

Middle $(n=562)$

Richer $(n=558)$

Richest $(n=637)$

Number of living sons

$0(n=692)$

$1(n=753)$

$2(n=683)$

$3(n=430)$

More than $3(n=231)$

Number of living daughters

$0(n=725)$

$1(n=824)$

$2(n=587)$

$3(n=326)$

More than $3(n=327)$

Table 2.

Binary logistic regression model of contraceptive utilization (weighted)
Experience of $G B V$

No $(n=1846)$

Yes $(n=943)$

Note(s) $*$ *value $<0.05 ; * * 223 *$

$$
\begin{array}{ll}
\multicolumn{2}{c}{\text { Reference category }} \\
2.007^{* *} & (1.471-2.739) \\
2.662^{* *} & (1.937-3.659) \\
2.658^{* *} & (1.893-3.732) \\
4.352^{* *} & (3.010-6.294)
\end{array}
$$

\begin{tabular}{cc}
\multicolumn{2}{c}{ Reference category } \\
$4.677^{* *}$ & $(3.462-6.317)$ \\
$9.147^{* *}$ & $(6.656-12.569)$ \\
$14.322^{* *}$ & $(9.97-20.558)$ \\
$20.208^{* *}$ & $(13.185-30.971)$
\end{tabular}

\begin{tabular}{ll}
\multicolumn{2}{c}{ Reference category } \\
$2.822^{* *}$ & $(2.169-3.671)$ \\
$3.356^{* *}$ & $(2.508-4.491)$ \\
$5.081^{* *}$ & $(3.610-7.152)$ \\
$5.471^{* *}$ & $(3.813-7.850)$
\end{tabular}

Reference category
(1.010-1.481)

\begin{tabular}{lr}
\multicolumn{2}{c}{ Reference category } \\
0.993 & $(0.792-1.245)$ \\
0.886 & $(0.674-1.164)$ \\
$0.346^{* *}$ & $(0.206-0.582)$ \\
1.884 & $(0.775-4.581)$ \\
$0.395^{*}$ & $(0.173-0.904)$
\end{tabular}

\begin{tabular}{lr}
\multicolumn{2}{c}{ Reference category } \\
1.143 & $(0.507-2.577)$ \\
0.895 & $(0.398-2.012)$ \\
0.791 & $(0.348-1.798)$ \\
0.734 & $(0.320-1.688)$ \\
0.578 & $(0.247-1.355)$ \\
$0.387^{*}$ & $(0.164-0.917)$
\end{tabular}

\begin{tabular}{lr}
\multicolumn{2}{c}{ Reference category } \\
$1.372^{*}$ & $(1.035-1.820)$ \\
$1.677^{* *}$ & $(1.258-2.235)$ \\
$2.074 * *$ & $(1.476-2.914)$
\end{tabular}

$$
\begin{gathered}
\text { Reference category } \\
1.244^{*}
\end{gathered}
$$

\begin{tabular}{ll}
\multicolumn{2}{c}{ Reference category } \\
$1.590^{* *}$ & $(1.151-2.195)$ \\
$1.813^{* *}$ & $(1.306-2.517)$ \\
$1.564^{*}$ & $(1.101-2.220)$ \\
$2.034^{* *}$ & $(1.396-2.964)$
\end{tabular}

\begin{tabular}{cc}
\multicolumn{2}{c}{ Reference category } \\
$3.688^{* *}$ & $(2.657-5.121)$ \\
$6.081^{* *}$ & $(4.329-8.541)$ \\
$13.258^{* *}$ & $(9.082-19.354)$ \\
$8.644^{* *}$ & $(5.569-13.417)$
\end{tabular}

\begin{tabular}{lr}
\multicolumn{2}{c}{ Reference category } \\
$1.884^{* *}$ & $(1.428-2.486)$ \\
$2.896^{* *}$ & $(2.141-3.917)$ \\
$4.122^{* *}$ & $(2.915-5.827)$ \\
$4.374^{* *}$ & $(3.021-6.332)$
\end{tabular}

Reference category
$1.207 \quad(0.993-1.467)$ 
with contraception use. Women with secondary education were more likely to use contraception than women who had no education (OR: 2.650, $p$-value $<0.010$; Table A1). Women in the middle-income group were 2.5 times more likely to use contraceptive methods than women in the poorest group (OR: 2.518, $p$-value $<0.0101$; Table A1).

In use of modern contraceptive methods (Table A2), spousal communication and joint decision-making increased the likelihood of condom use (one of the most popular methods). Women who made contraception decisions with their husband or partner were more likely to use condoms compared to the reference group, only women decided to use contraception (OR: $1.648, p$-value $<0.010$ )

\section{Discussion}

In this study, the results indicated that women age 45-49 years old were less likely to use contraception and modern contraceptive methods. These results could be explained that women aged 45-49 years old had a certain number of living children. They might have infrequent intercourse with their husband or partner (Islam \& Hasan, 2016). This age is also close to the menopause period among women; thus, they might believe that it is less likely they will get pregnant at this age (Islam \& Hasan, 2016).

Women's higher education significantly increased the likelihood of contraceptive uptake and use of modern contraceptive methods. This finding is consistent with findings of previous studies described in the literature review. Women's education level is a basic measurement of their socioeconomic status and reflects women's autonomy (Saleem \& Bobak, 2005). Most Pakistani women residing in rural areas have less access to education or employment opportunities than women living in urban areas (Tarar \& Pulla, 2014). Rural women are unpaid workers, expected to contribute to agricultural activities, and not allowed to go out to earn a living (Tarar \& Pulla, 2014). This makes women more dependent on their husbands or partners; therefore, rural women's autonomy is low, and they have less decisionmaking power and rely on their husband's decisions for seeking health services or even using family planning (Saleem \& Bobak, 2005). This explains why women in this study who have higher education are more likely to use contraception and modern contraceptive methods than women who have lower education. Women who have higher educational qualification might have better knowledge of SRH. They also have higher socioeconomic status in society with stable occupations and live in places where it is easier for them to access health facilities, including family planning services.

Compared to women in the poorest group, higher household income increased the likelihood of contraception use and modern contraceptive methods. This result was consistent with previous regional studies, such as Mohsena \& Kamal (2014). The wealth index is also a basic measurement of women's socioeconomic status. Women with a higher wealth index usually live in better conditions and have easier access health facilities, including family planning services (Saleem \& Bobak, 2005). They can afford the cost of contraception. Their autonomy is normally higher than that of poorer women. Thus, it is easier for wealthier women to be involved in decision-making with their husband or partner, and these women have more autonomy in deciding issues related to their health (Mohsena \& Kamal, 2014; Osmani, Reyer, Osmani, \& Hamajima, 2015).

Women who reside in a better family condition with higher wealth index, might have husbands or partners with higher education and economic levels. Meanwhile, the husband normally plays an important role in deciding on health service-seeking behavior in a family. Women who have husbands or partners with higher education used more contraception and modern contraceptive methods than women who had husbands or partners with lower education, according to the Pearson chi-square test in the preliminary findings from the descriptive analysis. 
FREP 1,1

Media exposure to family planning was positively associated with use of contraception and use of modern contraceptive methods. Women who were exposed to family planning in media channels were more likely to use contraception and modern contraceptive methods compared to women who were not exposed to information in media channels. This result was expected and in line with the findings of the previous studies discussed in the literature review.

The development of technology has contributed to the effectiveness of health intervention programs. Mass media campaigns are one of the strategies for increasing healthy behavior, including promoting knowledge and changing attitudes toward family planning (Jacobs, Marino, Edelman, Jensen, \& Darney, 2017). Mass media including radio, television and newspaper can reach a very large audience (Jacobs et al., 2017). Therefore, women might have more access to family planning information and be more familiar with family planning, which can affect their attitudes and ideas about desirable lifestyles and contraception (Goni \& Rahman, 2012). Moreover, information in official mass media channels, such as television, radio and newspaper, is more trusted by audiences (Goni \& Rahman, 2012).

The number of living sons, as well as daughters, was statistically significantly associated with contraceptive uptake and use of modern contraceptive methods. Women who had a higher number of living children were more likely to use contraception and modern contraceptive methods than women who had a lower number of living children. Having a certain number of sons increased the likelihood of using contraception and using modern contraceptive methods when compared with living daughters.

These findings reflect a cultural preference for sons. Pakistan is one of the countries with this cultural preference. It is influenced by the patriarchal social system in which the level of female empowerment is lower than that of male empowerment (Facio, 2013; Nasrullah \& Bhatti, 2012). Similar to many countries in Asia, Pakistan has a patrilineal inheritance system, and daughters are normally viewed as a heavier economic burden than sons (Channon, 2017; Nasrullah \& Bhatti, 2012), because a woman's family has to pay a large dowry when she marries, and the participation of women in the labor force is extremely low (Channon, 2017). Compared to other countries with available data, Pakistan has a much higher preference for sons than any other country, including India - where the extremely high preference for sons results in high levels of sex-selective abortions (Channon, 2017). The preference for sons not only affects contraceptive uptake behavior but also influences use of modern contraceptive methods (Channon, 2015). This suggests that eliminating the preference for sons might increase contraception use and modern contraceptive methods. It also addresses fertility issues, avoids sex ratio imbalances and improves SRH.

The participation of men and women in decision-making regarding contraception use was a good predictor of the use of condoms (Table A2). Women who jointly made decisions with their husbands or partners were more likely to have their husband use a condom than women who decided by themselves.

The results also showed that women whose husbands made most decisions regarding contraception use were more likely to use condoms than women who joined in the decisionmaking process. In the context of Pakistan, men make most of the decisions on healthcare service seeking and women depend on their husband or partners, especially in terms of household finance (Ali et al., 2011; Nasrullah \& Bhatti, 2012; Tarar \& Pulla, 2014; Zakar, Zakar, \& Kraemer, 2013). Therefore, if women are allowed by their husbands or partners to use contraception, it would be easier to access family planning services and afford modern contraceptive methods.

The results also show that women who experienced GBV were more likely to use contraception than women who had not experienced violence. This finding was in line with the finding of Dalal et al. (2012) in Bangladesh and Emenike et al. (2008) in Kenya. The higher level of contraception use among women who experienced violence might be associated with fear of pregnancy in unfavorable conditions (Siddique, Zakar, Farhat, \& Deeba, 2019). These 
findings were consistent with some evidence that abused women are likely to control their bodies in term of SRH decision-making (Siddique et al., 2019). Women might be aware of the consequences of their husband's or partner's violent behavior toward them. Therefore, the women were more likely to take the initiative to control the number of children born in a violent relationship (Dalal \& Lindqvist, 2012; Siddique et al., 2019).

Among women who experienced violence, the results showed that higher education increased the likelihood of contraception use, and women with a higher wealth index were also more likely to use contraception than the poorest women. Women in the KPK and Balochistan regions, which are known as less developed regions with lower literacy and wealth index compared to other regions, were less likely to use contraceptive methods to prevent unintended pregnancy than women in Punjab, the most populous region (Rehman, Jingdong, \& Hussain, 2015). This means that abused women in better living and working conditions might have a better perspective on their unfavorable condition and be aware of the effect of their husband's or partner's violent practices toward them (Siddique et al., 2019). Healthcare services, including family planning services, might be more available and convenient for women in better living conditions (Punjani, 2018). Therefore, these women have easier access to family planning services to prevent unwanted pregnancy than women in worse conditions.

The rate of GBV is very high in Pakistan with about $34 \%$ of Pakistani women having experienced at least one type of GBV. However, this led to higher contraception use among women who experienced GBV. GBV results in many adverse health outcomes and forces women to protect themselves in unfavorable conditions. Compared to women residing in better living and working conditions, women who reside in less developed areas and have less education and a lower wealth index face many problems related to their $\mathrm{SRH}$, such as unmet family planning needs and official support services about GBV when domestic violence is considered a private issue and the government does not have an efficient mechanism to support victims of GBV.

\section{Limitations of the study}

Although the dataset is considered nationally representative data on health, this crosssectional study reflects only an overview, contraceptive method uptake and use of modern contraceptive methods among Pakistani women. The results do not show underlying causes to explain contraception use behaviors.

The use of secondary data limited the variety of important variables that should be investigated, including women's knowledge of SRH, women's attitude toward SRH and family planning, skills of a healthcare provider in counseling family planning, and other barrier variables, such as transportation and willingness to pay for contraception methods.

Although the survey was conducted in a large sample size, the number of participants who met all criteria of this study was small. This might call into question the representativeness of these findings for the population.

The sensitivity of the topic is considered another challenge when collecting data (Basu, Jaising, \& Collective, 2005). Women might be hesitant to share their GBV experience (Basu et al., 2005). The experience of GBV is also hard to define and depends on the feeling of each person, especially emotional violence. An additional limitation is that information on the frequency of GBV is not provided in the data set.

\section{Recommendations}

Based on the findings of this study and those from previous studies, there are some recommendations to promote contraception use and use of modern contraception methods among Pakistani women. 
FREP 1,1

Because of disparity in socioeconomic conditions, women who have less education, live in poorer regions and have a lower wealth index are less likely to access information on family planning and health facilities. Therefore, the government of Pakistan should create a strategy for promoting a national SRH program and enhance the availability of family planning services in all communities to respond to the demand for family planning, especially for less developed areas where women face many barriers, such as transportation and affordability of contraception. Moreover, integrating comprehensive sexuality education into school programs should be considered. Young people can be equipped with SRH knowledge and skills and effective communication skills for use with spouses, children and parents at a young age.

The position of women in society is one of the biggest concerns in health promotion programs. When women are considered the property of men, they cannot make a decision without permission from their husbands, fathers or brothers (Ashraf, Abrar-U1Haq, \& Ashraf, 2017). Therefore, women empowerment programs to promote the position of women in family and society should be developed and integrated into the national call for action. That improves the meaningful participation of women in the labor force, allows them independence in the economy and grants them more power in making decisions about their health and their bodies. Meanwhile, male involvement and spousal communication promotion should be taken into consideration as important components.

The government should develop an efficient mechanism to support victims of GBV. The mechanism should ensure the safety, privacy and confidentiality of the victims. Supporters should have a neutral attitude and be respectful to and supportive of victims.

\section{Conclusions}

This study aimed to identify the prevalence of contraception use among Pakistani women, as well as assess the factors influencing the utilization of contraception with a focus on GBV. The findings demonstrated that the experience of GBV was a good predictor in explaining variation in contraception use. Women who experienced violence are more likely to use contraception than women who had not experienced violence. Higher contraception use among women who experienced violence might be associated with fear of pregnancy in unfavorable conditions.

From the results of this study and those from previous studies, some associations between contraception use and risk factors were identified. Policymakers can use these findings to develop policies and national programs for improving the prevalence of contraception use and model contraceptive methods among Pakistani women.

\section{References}

Ali, T. S., Krantz, G., Gul, R., Asad, N., Johansson, E., \& Mogren, I. (2011). Gender roles and their influence on life prospects for women in urban Karachi, Pakistan: A qualitative study. Global Health Action, 4, 7448.

Ashraf, S., Abrar-Ul-Haq, M., \& Ashraf, S. (2017). Domestic violence against women: Empirical evidence from Pakistan. Pertanika Journal of Social Sciences \& Humanities, 25, 1401-1418.

Aslam, S. K., Zaheer, S., Qureshi, M. S., Aslam, S. N., \& Shafique, K. (2016). Socio-economic disparities in use of family planning methods among Pakistani women: Findings from Pakistan demographic and health surveys. Plos One, 11, e0153313.

Basu, A., Jaising, I., \& Collective, L. (2005). Violence Against Women: A Statistical Overview, Challenges and Gaps in Data Collection and Methodology and Approaches for Overcoming them. Division for the Advancement of Women. 
Channon, M. D. (2015). Son preference, parity progression and contraceptive use in South Asia. Population Horizons, 12, 24-36.

Channon, M. D. (2017). Son preference and family limitation in Pakistan: A parity-and contraceptive method-specific analysis. International Perspectives on Sexual and Reproductive Health, 43, 99-110.

Dalal, K., \& Lindqvist, K. (2012). A national study of the prevalence and correlates of domestic violence among women in India. Asia Pacific Journal of Public Health, 24, 265-277.

Dalal, K., Andrews, J., \& Dawad, S. (2012). Contraception use and associations with intimate partner violence among women in Bangladesh. Journal of Biosocial Science, 44, 83.

Emenike, E., Lawoko, S., \& Dalal, K. (2008). Intimate partner violence and reproductive health of women in Kenya. International Nursing Review, 55, 97-102.

Facio, A. (2013), What is Patriarchy?, (Translated from Spanish by Michael Solis).

Gomez, A. M. (2011). Sexual violence as a predictor of unintended pregnancy, contraceptive use, and unmet need among female youth in Colombia. Journal of Women's Health, 20, 1349-1356.

Goni, A., \& Rahman, M. (2012). The impact of education and media on contraceptive use in Bangladesh: A multivariate analysis. International Journal of Nursing Practice, 18, 565-573.

Hadi, A. (2017). Patriarchy and GBV in Pakistan. European Journal of Social Science Education and Research, 4, 297-304.

Hindin, M. J., Kishor, S., \& Ansara, D. L. (2008). Intimate Partner Violence among Couples in 10 PDHS Countries: Predictors and Health Outcomes. Macro International.

Hong Nguyen, P., Van Nguyen, S., Quang Nguyen, M., Truong Nguyen, N., Keithly, S., Tran Mai, L., ... Quynh Pham, H. (2012). The association and a potential pathway between GBV and induced abortion in Thai Nguyen province, Vietnam. Global Health Action, 5, 19006.

Howse, K. and Nanitashvili, N. (2014), Contraceptive Methods Used by Younger Women: South Asia.

Imran, M., Nasir, J. A., \& ZaidI, S. A. A. (2015). Demographic socio-economic characteristics of women and contraceptive use in Pakistan. Journal of University Medical \& Dental College, 6 , $47-54$.

Islam, S., \& Hasan, M. (2016). Women knowledge, attitude, approval of family planning and contraceptive use in Bangladesh. Asia Pacific Journal of Multidisciplinary Research, 4, 76-82.

Jacobs, J., Marino, M., Edelman, A., Jensen, J., \& Darney, B. (2017). Mass media exposure and modern contraceptive use among married West African adolescents. The European Journal of Contraception \& Reproductive Health Care, 22, 439-449.

Miller, E., Jordan, B., Levenson, R., \& Silverman, J. G. (2010). Reproductive coercion: Connecting the dots between partner violence and unintended pregnancy. Contraception, 81, 457-459.

Mohsena, M., \& Kamal, N. (2014). Determinants of contraceptive use in Bangladesh. Ibrahim Medical College Journal, 8, 34-40.

Mumtaz, Z., Salway, S., Shanner, L., Bhatti, A., \& Laing, L. (2011). Maternal deaths in Pakistan: Intersection of gender, caste, and social exclusion. BMC International Health and Human Rights, 11, S4.

Namasivayam, A., Lovell, S., Namutamba, S., \& Schluter, P. J. (2020). Predictors of modern contraceptive use among women and men in Uganda: A population-level analysis. BMJ Open, 10, e034675.

Nasrullah, M., \& Bhatti, J. A. (2012). Gender inequalities and poor health outcomes in Pakistan: A need of priority for the national health research agenda. Journal of College of Physicians and Surgeons Pakistan, 22, 273-274.

Osmani, A. K., Reyer, J. A., Osmani, A. R., \& Hamajima, N. (2015). Factors influencing contraceptive use among women in Afghanistan: Secondary analysis of Afghanistan health survey 2012. Nagoya Journal of Medical Science, 77, 551.
Contraceptive use among Pakistani women 
FREP 1,1
Pallitto, C. C., Campbell, J. C., \& O'Campo, P. (2005). Is intimate partner violence associated with unintended pregnancy? A review of the literature. Trauma, Violence, \& Abuse, 6, 217-235.

Paul, A. (2010). Poverty and domestic violence. Counter Currents.

PDHS (2008). National Institution of Population Studies (NIPS) Pakistan and ICF International. 2007. Pakistan Demographic and Health Survey 2006-07. Islamabad, Pakistan, and Calverton, MD: National Institute of Population Studies and Macro International.

PDHS (2013). National Institute of Population Studies (NIPS) Pakistan and ICF International. Pakistan Demographic and health survey 2012-2013. Islamabad, Pakistan, and Calverton, MD: NIPS and ICF International.

PDHS (2019). National Institute of Population Studies (NIPS) Pakistan and ICF International. Pakistan Demographic and Health Survey 2017-2018.

Punjani, N. (2018). Determinants associated with unmet need for family planning in Pakistan. Journal of Women's Health, Issues Care, 7(1), 2.

Rehman, A., Jingdong, L., \& Hussain, I. (2015). The province-wise literacy rate in Pakistan and its impact on the economy. Pacific Science Review B: Humanities and Social Sciences, 1, 140-144.

Saleem, S., \& Bobak, M. (2005). Women's autonomy, education and contraception use in Pakistan: A national study. Reproductive Health, 2, 8.

Saqib, M., \& Ahmad, S. M. (2014). Root causes of low female literacy in FATA Pakistan (a case study of Jalozai camp). International Journal of Academic Research in Business and Social Sciences, 4, 457.

Sarkar, N. (2008). The impact of intimate partner violence on women's reproductive health and pregnancy outcome. Journal of Obstetrics and Gynaecology, 28, 266-271.

Siddique, K., Zakar, R., Farhat, N., \& Deeba, F. (2019). Intimate partner violence and its association with contraceptive use among women in Pakistan. Pakistan Journal of Psychological Research, 10, 157-173.

Silverman, J. G., Gupta, J., Decker, M. R., Kapur, N., \& Raj, A. (2007). Intimate partner violence and unwanted pregnancy, miscarriage, induced abortion, and stillbirth among a national sample of Bangladeshi women. BJOG: An International Journal of Obstetrics \& Gynaecology, 114, 1246-1252.

Tarar, M. G., \& Pulla, V. (2014). Patriarchy, gender violence and poverty amongst Pakistani women: A social work inquiry. International Journal of Social Work and Human Services Practice, 2, 56-63.

World Health Organization (2005). WHO Multi-country Study on Women's Health and Domestic Violence Against Women: Initial Results on Prevalence, Health Outcomes and Women's Responses. World Health Organization.

Zakar, R., Zakar, M. Z., \& Kraemer, A. (2013). Men's beliefs and attitudes toward intimate partner violence against women in Pakistan. Violence Against Women, 19, 246-268.

\section{Corresponding author}

Thao Thi Nguyen can be contacted at: thaovinguyen3010@gmail.com 
Appendices

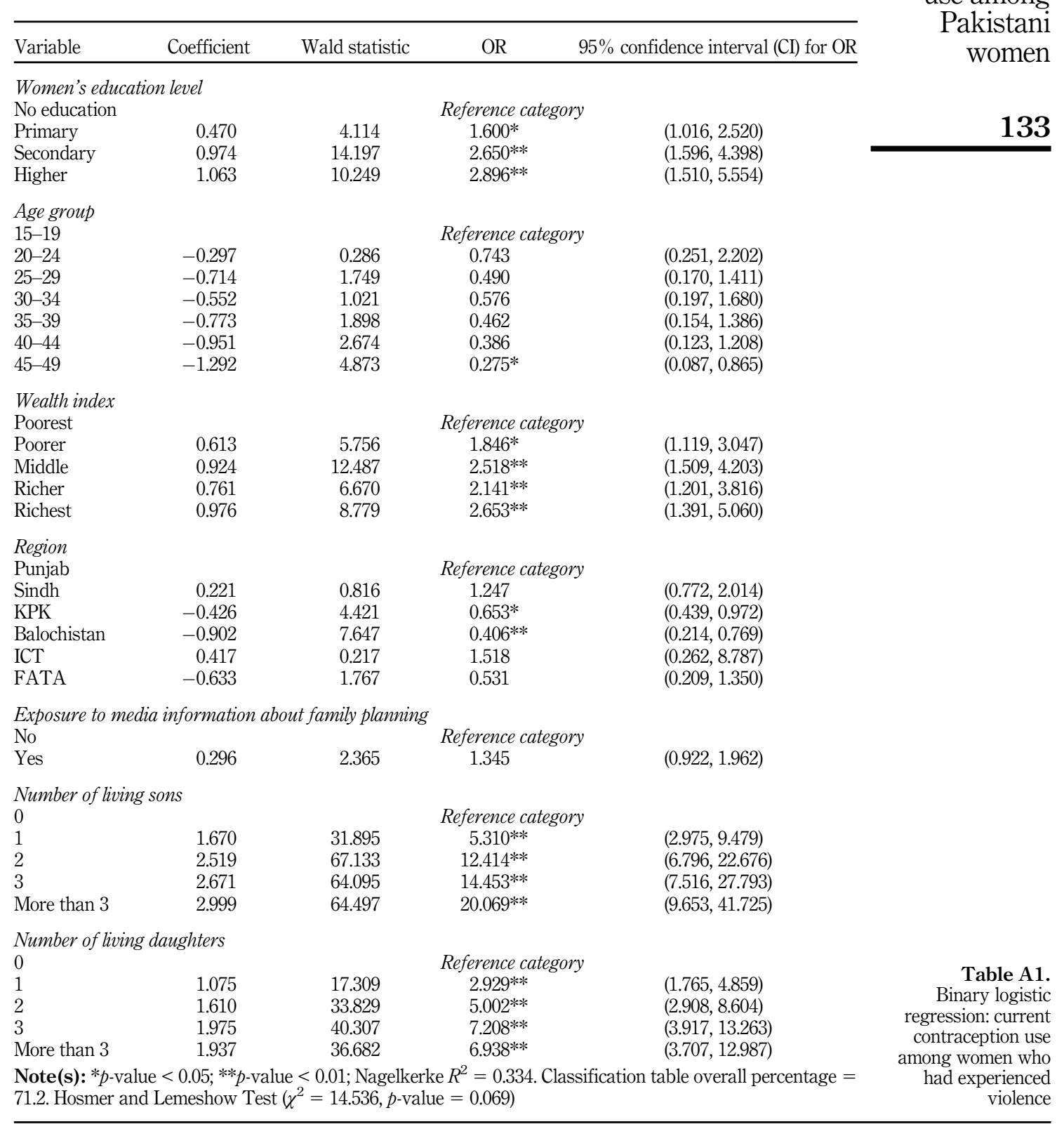

Contraceptive

use among Pakistan 133 


\section{FREP 1,1}

134

\begin{tabular}{|c|c|c|c|c|}
\hline Variable & Coefficient & Wald statistic & OR & $95 \% \mathrm{CI}$ for $\mathrm{OI}$ \\
\hline \multicolumn{5}{|c|}{ Women's education level } \\
\hline No education & \multicolumn{4}{|c|}{ Reference category } \\
\hline Primary & 0.362 & 2.127 & 1.437 & $(0.883,2.337)$ \\
\hline Secondary & 0.554 & 5.395 & $1.740 *$ & $(1.090,2.776)$ \\
\hline Higher & 0.248 & 0.773 & 1.281 & $(0.737,2.226)$ \\
\hline \multicolumn{5}{|l|}{ Age group } \\
\hline $15-19$ & \multicolumn{4}{|c|}{ Reference category } \\
\hline $20-24$ & 0.249 & 0.123 & 1.282 & $(0.319,5.154)$ \\
\hline $25-29$ & -0.157 & 0.050 & 0.855 & $(0.217,3.367)$ \\
\hline $30-34$ & -0.506 & 0.511 & 0.603 & $(0.151,2.414)$ \\
\hline $35-39$ & -0.374 & 0.270 & 0.688 & $(0.168,2.817)$ \\
\hline $40-44$ & -1.457 & 3.778 & 0.233 & $(0.054,1.012)$ \\
\hline $45-49$ & -0.911 & 1.457 & 0.402 & $(0.092,1.765)$ \\
\hline
\end{tabular}

Wealth index

Poorest

Poorer

0.955

Middle

1.127

Richer

Richest

1.472

1.068

$-0.484$

0.855

0.078

0.569

Region

Punjab

Sindh

KPK

Balochistan

$-0.858$

FATA

0.499

Reference category

$\begin{array}{rll}5.797 & 2.598^{*} & (1.194,5.653) \\ 8.404 & 3.085^{* *} & (1.440,6.608) \\ 13.344 & 4.357^{* *} & (1.978,9.597) \\ 6.636 & 2.908^{* *} & (1.291,6.552)\end{array}$

Experience of $G B V$

No

Yes

Reference category

$\begin{array}{rr}5.893 & 0.616 \\ 13.317 & 2.351 \\ 0.028 & 1.081 \\ 0.943 & 1.767 \\ 0.817 & 0.424\end{array}$

$(0.417,0.911)$

(1.486, 3.722)

$(0.432,2.705)$

$(0.560,5.580)$

(0.066, 2.726)

Exposure to media information about family planning

No

Yes

0.423

Number of living sons

0

$1-0.050$

$2-0.690$

3

More than 3

$-0.508$

$-1.643$

Number of living daughters

0

$1-0.579$

$2-0.742$

$3-0.787$

$-0.787$
More than 3

Decision-makers for contraception use

Mostly respondent

Mostly husband/partner $\quad 1.461$

Joint decision

1.084

\begin{tabular}{ll}
\multicolumn{2}{c}{ Reference category } \\
6.923 & $2.956^{*}$ \\
6.498 & $1.648^{* *}$
\end{tabular}

$(1.285,12.788)$

$(1.195,6.803)$
Binary logistic regression: condom use among women who used contraception at the time of the survey
Note(s): $* p$-value $<0.05 ; * * p$-value $<0.01$; Nagelkerke $R^{2}=0.313$. Classification table overall percentage $=$ 75.3. Hosmer and Lemeshow Test $\chi^{2}=10.212, p$-value $\left.=0.250\right)$

\begin{tabular}{rrr}
\multicolumn{2}{r}{ Reference category } & \\
0.028 & 0.951 & $(0.529,1.710)$ \\
4.813 & $0.502^{*}$ & $(0.271,0.929)$ \\
2.131 & 0.601 & $(0.304,1.190)$ \\
12.675 & $0.193^{* *}$ & $(0.078,0.478)$
\end{tabular}

\begin{tabular}{lll}
\multicolumn{2}{r}{ Reference category } & \\
5.896 & $0.561^{*}$ & $(0.352,0.894)$ \\
7.401 & $0.476^{* *}$ & $(0.279,0.813)$ \\
6.791 & $0.455^{* *}$ & $(0.252,0.823)$ \\
6.110 & $0.431^{*}$ & $(0.221,0.840)$
\end{tabular}

